DOI: $10.1113 / J P 280569$

\title{
The effects of maternal position, in late gestation pregnancy, on placental blood flow and
} oxygenation: an MRI study

Running Title MRI study of effect of maternal position on placental function

Keywords: Placental oxygenation; magnetic resonance imaging; maternal position, pregnancy

Authors:

Sophie Couper ${ }^{1}$, Alys Clark ${ }^{2}$, John M D Thompson ${ }^{1,3}$, Dimitra Flouri ${ }^{4}$, Rosalind Aughwane ${ }^{5}$, Anna L David $^{5}$, Andrew Melbourne ${ }^{4}$, Ali Mirjalili' ${ }^{6}$, Peter R Stone. ${ }^{1}$

1 Department of Obstetrics and Gynaecology, University of Auckland, Private Bag 92019 Auckland 1142, New Zealand

Sophie Couper; scou918@aucklanduni.ac.nz

Peter Stone; p.stone@auckland.ac.nz

2 Auckland Bioengineering Institute, University of Auckland, Private Bag 92019 Auckland 1142 New Zealand

Alys Clark; alys.clark@auckland.ac.nz

3 Department of Paediatrics and Child Health, Private Bag 92019 Auckland 1142 University of Auckland, New Zealand

John Thompson; j.thompson@auckland.ac.nz

4 School of Biomedical Engineering and Imaging, Kings College London, 1 Lambeth Palace Road London, SE1 7EU United Kingdom.

Dimitra Flouri; d.flouri@ucl.ac.uk

Andrew Melbourne; andrew.melbourne@kcl.ac.uk

This is an Accepted Article that has been peer-reviewed and approved for publication in The Journal of Physiology, but has yet to undergo copy-editing and proof correction. Please cite this article as an 'Accepted Article'; doi: 10.1113/JP280569.

This article is protected by copyright. All rights reserved. 
5 Elizabeth Garrett Anderson Institute for Women's Health, University College Huntley Street, London, WC1E6AU, United Kingdom.

Rosalind Aughwane; rosalind.pratt@alumni.ucl.ac.uk

Anna David; anna.david@uclh.nhs.uk

6 Department of Anatomy and Medical Imaging, University of Auckland, Private Bag 92019

Auckland 1142 New Zealand

Ali Mirjalili; a.mirjalili@auckland.ac.nz

Corresponding author

Peter Stone

Department of Obstetrics and Gynaecology

The University of Auckland

Private Bag 92019

Auckland 1142

New Zealand

Phone: +64 (0) 93737599

p.stone@auckland.ac.nz

Table of contents category: Placenta, Pregnancy and Perinatal Physiology

Key Point summary:

- Maternal supine sleep position in late pregnancy is associated with an increased risk of stillbirth.

- Maternal supine position in late pregnancy reduces maternal cardiac output and uterine blood flow.

- Using MRI, this study shows that compared to the left lateral position, maternal supine position in late pregnancy is associated with reduced uteroplacental blood flow, oxygen transfer across the placenta with an average $6.2 \%$ reduction in oxygen delivery to the fetus and an average $11 \%$ reduction in fetal umbilical venous blood flow. 
Abstract:

Maternal sleep position in late gestation is associated with an increased risk of stillbirth though the pathophysiological reasons for this are unclear. Studies using MRI have shown that compared with lateral positions, lying supine causes a reduction in cardiac output, reduced abdominal aortic blood flow and reduced vena caval flow which is only partially compensated for by increased flow in the azygos venous system. Using functional MRI techniques, including an acquistion termed DiffusionRelaxation Combined Imaging of the Placenta (DECIDE), which combines diffusion weighted imaging and T2 relaxometry, blood flow and oxygen transfer were estimated in the maternal, fetal and placental compartments when subjects were scanned both supine and in left lateral positions. In late gestation pregnancy, lying supine caused a $23.7 \%(\mathrm{p}<0.0001)$ reduction in total internal iliac arterial blood flow to the uterus. In addition, lying in the supine position caused a $6.2 \%(p=0.038)$ reduction in oxygen movement across the placenta. The reductions in oxygen transfer to the fetus, termed delivery flux, of $11.2 \%(\mathrm{p}=0.0597)$ and in fetal oxygen saturation of $4.4 \%(\mathrm{p}=0.0793)$ did not reach statistical significance. It is concluded that even in healthy late gestation pregnancy, maternal position significantly affects oxygen transfer across the placenta and may in part provide an explanation for late stillbirth in vulnerable fetuses.

\section{$\underline{\text { Introduction }}$}

Stillbirth is a devastating outcome for a pregnancy. This is a worldwide problem with an estimated rate of 18.4/1000 births after 28 week's gestation (Lawn et al. 2016). Even in high income countries, the rate of stillbirth after 28 weeks varies from 1.7/1000 to 8.7/1000 births (Flenady et al., 2016). Excluding congenital anomalies and preterm labour, unexplained stillbirth is the most common reason for the death of a fetus in New Zealand and other high income nations (Perinatal and Maternal Morality Review Committee (PMMRC), 2018; Reinebrant, 2018). In New Zealand, as in other high income countries, the rate of unexplained stillbirth occurring after 28 week's gestation has not changed significantly since 2012, unlike other causes of stillbirth such as maternal hypertension, fetal growth restriction, or hypoxic peripartum events, where reductions in the rate of stillbirth have been noted (Flenady et al., 2016).

Considerable research efforts have been focused on seeking causes and modifiable risk factors to reduce the burden of these perinatal losses (Wojcieszek et al., 2018; Cronin et al., 2019). Epidemiological studies have found that women who went to sleep in a supine position in late 
gestation had a 2 to 3 -fold increased risk of stillbirth, compared to women who went to sleep on their left side (Stacey et al., 2011; Gordon et al., 2015; Heazell et al., 2018; Cronin et al., 2019). A triple risk model developed by Warland and Mitchell suggests that fetal risk, combined with a maternal factor, such as preeclampsia and an acute event or stressor, such as maternal supine sleep position, causing reduced uteroplacental, and fetoplacental blood flow, creates a scenario of increased risk of stillbirth. The vulnerable fetus and mother do not compensate for the stressor and this has been proposed to lead to an increased risk of intrauterine death (Warland \& Mitchell, 2014). A recent metaanalysis conducted on sleep position stillbirth studies identified going to sleep position as an independent risk factor for stillbirth, thus, sleep position itself may be sufficient to explain these stillbirths (Cronin et al., 2019). Studies showing increased risk of stillbirth with supine sleep collectively suggest that there is an underlying pathophysiological process associated with intrauterine death. As sleep position is a modifiable risk factor for stillbirth, an understanding of the mechanisms associated with this risk is important.

Two primary mechanisms for the elevated risk of stillbirth with supine sleep have been proposed (Cronin et al., 2020): increased maternal sleep disordered breathing when supine leading to maternal hypoxia, and a compression of the inferior vena cava that has been shown to decrease maternal cardiac output when supine in late pregnancy (Humphries et al., 2019) which could lead to fetal hypoxia. No study has assessed the impact of maternal position on the delivery of blood and oxygen to the placenta. Invasive studies of utero-placental blood flow in human pregnancy are not possible. Ultrasound has become the predominant form of imaging used in pregnancy since the technique was first introduced in 1958. Comparatively, MRI is a newer form of imaging, beginning clinical use in the 1980s and whilst theoretical fetal risks are still being considered when used in pregnancy, no longterm effects have been observed (Lum \& Tsiouris 2020). Functional MRI techniques, though not routinely used in pregnancy, can measure parameters apart from structure, such as blood flow, and more recently oxygen diffusion across the placenta (Aughwane et al., 2020). Whilst ultrasound has been used extensively to estimate utero-placental and fetal blood flow indices using Doppler ultrasound, MRI techniques can interrogate the movement of molecules and oxygenation, as well as measure blood flow in tissues and circulatory compartments beyond the capabilities of ultrasound.

Most MRI techniques for imaging the placenta were developed initially from cerebral MRI (Bihan et al., 1988; Siauve et al., 2015), however, the placenta differs from the brain in that the placenta has two circulations, maternal and fetal (Moore et al., 2000). Multiple MRI techniques have been attempted in human and animal studies to find an efficient method that can be utilised in clinical practice and in research to image the placenta. Four main MRI techniques have been developed to 
measure placental blood flow and oxygenation, these being arterial spin labelling (ASL) and velocity selective labelling (Derwig et al., 2013; Shao et al., 2018; Zun \& Limperopoulos, 2018; Ludwig et al., 2019), blood oxygen level dependent imaging (BOLD) (Huen et al., 2013; Sørensen et al., 2013; Avni et al., 2016; Schabel et al., 2016; Luo et al., 2017; Ginosar et al., 2018; Sinding et al., 2018), diffusion weighted imaging (DWI, including Intravoxel Incoherent Motion (IVIM) for measuring perfusion) (Moore et al., 2000; Manganaro et al., 2010; Capuani et al., 2017; You et al., 2017; Jakab et al., 2018; Melbourne et al., 2019; Siauve et al., 2019), and dynamic-contrast enhanced imaging (DCE-MRI) (Frias et al., 2015; Yadav et al., 2016; Ludwig et al., 2019). DCE-MRI is the goldstandard but cannot be used in ongoing human pregnancies due to concerns regarding the injection of contrast agents into the circulation.

It is well established that maternal and fetal haemoglobin have different properties that protect oxygen transport in pregnancy, and potentially safeguard the fetus from reductions in oxygen supply (Carter, 2009; Avni et al., 2016; Melbourne et al., 2019). The differing haemoglobin composition in the fetus enables higher affinity for binding oxygen (Avni et al., 2016; Melbourne et al., 2019). In addition, the haematocrit differs between maternal and fetal blood (Soothill et al., 1986; Soothill et al., 1987). Thus whilst fetal vascular $\mathrm{PO}_{2}$ is low in comparison to that of the adult, the higher haemoglobin concentration and higher affinity for oxygen means that the fetus has a high oxygen content and saturation; a situation which provides an "oxygen margin of safety" if required (Richardson, 1989). Fetal haemoglobin also has a lower P50 value than adult blood, which ensures that in the low pressure fetal environment, oxygen can reach tissues with low partial pressure. In 2016, it was revealed that the oxygen-saturation curve, previously calculated by physiologists in the laboratory, can be derived through MRI (Avni et al., 2016). This paved the way for the different oxygen content of maternal and fetal haemoglobin to be utilized to separate out the maternal and fetal circulation with MRI. Using a combination of DWI-IVIM and T2 relaxometry, a novel acquisition has been developed which has the ability to differentiate between maternal and fetal contributions to uteroplacental blood flow and oxygen delivery across the human placenta (Melbourne et al., 2019). This process has been termed Diffusion-Relaxation Combined Imaging of the Placenta (DECIDE).

The aim of this study was to compare the effects of the maternal supine with left lateral decubitus (LLD) positions on the blood flow and oxygen delivery to the placenta, across the placenta and from the placenta to the fetus, in healthy late gestation pregnancy. Phase contrast MRI was used to measure flow in the large vessels and DECIDE to estimate intra-placental perfusion and oxygenation to determine whether previously reported changes in maternal cardiac output when moving from LLD to supine positions in late gestation (Humphries et al., 2019), are sufficient to impact upon placental oxygenation. 
Methods

Ethical Approval

Ethical approval was provided by the Health and Disabilities Ethics Committee of New Zealand, reference number 15/NTB/144/AM08. Informed consent and a separate MRI safety questionnaire were completed in writing prior to entry into this study. The procedures, approved by the Health and Disability Ethics Committees of the New Zealand Government, conformed to the standards set by the Declaration of Helsinki. The study was not registered as a clinical trial.

\section{Participant Recruitment}

Twenty two pregnant women were recruited in Auckland, New Zealand from December 2018 until September 2019 using social media, midwife clinics, posters and brochures. Criteria for inclusion in the study were; a healthy singleton uncomplicated pregnancy, between 34-38 weeks of gestation by early ( $1^{\text {st }}$ trimester) ultrasound, with a pre-pregnancy Body Mass Index (BMI) between 18 and 30. Women with multiple pregnancies, gestational hypertension (defined as new onset hypertension after 20 weeks gestation with no features of preeclampsia) or preeclampsia (defined as new onset hypertension after 20 weeks gestation and one or more of renal, haematological, hepatic neurological or fetal growth anomalies, (Lowe et al., 2015)), gestational diabetes (defined absence of pre-existing diabetes as a fasting glucose $\geq 5.5 \mathrm{mmol} / \mathrm{L}$ or a 2 hour value $\geq$ on a 75 gram oral glucose tolerance $\geq 9.0 \mathrm{mmol} / \mathrm{L}$ (Ministry of Health, 2014), fetal growth restriction (FGR) defined as ultrasound estimated fetal weight $<10^{\text {th }}$ percentile using customised centile charts (Gardosi et al., 2018), placenta praevia and pre-existing maternal conditions including cardiovascular, renal, diabetic and autoimmune conditions were excluded from the study.

Birth outcome data including, customised percentile birthweight (Gardosi et al., 2018) gestation, sex, condition at birth, need for resuscitation and/or admission to neonatal intensive care and presence of congenital anomalies were recorded to confirm normal pregnancy outcome. Mode of delivery and indications for abnormal delivery (instrumental vaginal or caesarean section) were also recorded as additional indicators of fetal condition.

Participants were asked to refrain from consuming caffeine or taking part in strenuous exercise in the two hours prior to the study. All studies were performed in the morning. An ultrasound assessment of fetal welfare was conducted prior to the MRI, by a qualified obstetrician with obstetric ultrasound 
expertise which included ultrasound estimation of amniotic fluid depth, presence of fetal movements and an umbilical arterial Doppler ultrasound pulsatility index $<95^{\text {th }}$ percentile (Acharya et al., 2005).

\section{MRI Protocol}

All MRI scans were performed on a 1.5 Tesla scanner, housed at the Centre for Advanced MRI (CAMRI), University of Auckland, New Zealand, by a qualified MRI technician. Two maternal positions were studied, left lateral decubitus (LLD) and supine to ensure that there were no systematic effects of order or time that could not be assessed. The starting position, either LLD or supine was randomly allocated using an Excel $^{\mathrm{R}}$ random number generator. The DECIDE analysis was performed blinded to maternal position. The MRI scans as described below were completed in both positions for each participant. Total scan time was approximately 1 hour, excluding time taken to change position. The time to acquire sequences was usually between 20 and 25 minutes.

Time in each position was similar as both the initial scout scans and the running of the MRI sequences used the same technical procedures. Participants were able to alert the technicians should they feel discomfort and were provided with headphones to listen to music of their choice during the scan procedures.

Participants were positioned head first in the MRI. In the supine position it was usually beneficial to place a pillow under the knees and in LLD a pillow was placed behind the back. The uterus was not manipulated away from the midline when the women lay supine. After the completion of the first position, the subjects rolled to the second position without mobilising. A 20-channel body matrix coil was placed over the centre to middle of the abdomen for acquiring images. The participants' heart rate (HR), and blood pressure (BP) were monitored and recorded throughout the duration of the MRI via a pulse oximeter and an automated BP cuff, which could be operated remotely from the control room. The pulse oximeter was also used for flow gating. In each position, first, localiser (scout) images, were completed in coronal and axial planes (voxel size $0.74 \mathrm{~mm} \times 0.74 \mathrm{~mm} \times 5 \mathrm{~mm}$ ). These enabled visualisation of the placenta, and the required blood vessels. Scanning was then undertaken to acquire the following images: 1. Phase contrast imaging (PC MRI) of internal iliac arteries, 2. PC MRI of fetal umbilical vein, 3. The DECIDE imaging procedure (Melbourne et al., 2019). 


\section{Phase Contrast Imaging of the Internal Iliac Arteries}

Axial slices were selected just below the bifurcation of the maternal common iliac arteries into the internal and external iliac arteries. PC MRI was acquired during a breath hold of 10 to 15 seconds. All images were obtained in the axial plane to the artery of interest at 90 degrees to the flow in the vessel (repetition time $(\mathrm{TR})=50-60 \mathrm{~ms}$, echo time $(\mathrm{TE})=3.1 \mathrm{~ms}$, field of view $(\mathrm{FOV})=450 \mathrm{~mm}^{2}$, FOV phase $=69.4 \%$, matrix $=256$ pixels, velocity encoding $($ VENC $)=200 \mathrm{~cm} / \mathrm{s}$, number of phases $=20$, time for each image $=12 \mathrm{~s}$, number of images $=20$, flip angle $=20$ degrees, voxel size $=1.6 \mathrm{~mm} \times 1.6$ $\mathrm{mm} \times 4.5 \mathrm{~mm}$ ). All parameters are heart rate dependent so may not be identical for all participants.

\section{Phase Contrast Imaging of the Umbilical Vein}

PC MRI was also acquired in the umbilical vein during a maternal breath hold with synthetic gating to a typical fetal heart rate (HR) of $150 \mathrm{bpm}$. Images were oversampled to allow for the effect of a variable fetal HR to be accounted for in post-processing. Scout images were used to manually identify a section of the umbilical cord from which to obtain a short axis with vessels visible. Repeat scanning in a subset of axial slices was sometimes needed to relocate the cord due to fetal movement since the initial scouts. Images were acquired under a maternal breath hold as before. PC MRI acquisition was in a single slice, with no parallel imaging at 90 degrees to the UV. A conventional gradient echo phase contrast sequence was used $(\mathrm{TR}=57.20 \mathrm{~ms}$, Field of FOV $=450 \mathrm{~mm}$, FOV Phase $=69.4 \%$, TE $=3.2 \mathrm{~ms}$, Matrix $=192-256$ pixels, $\mathrm{VENC}=50 \mathrm{~cm} / \mathrm{s}$, Flip angle $=20$ degrees, 1 average and 4 views per segment, Voxel size $=1.6 \mathrm{~mm} \times 1.6 \mathrm{~mm} \times 5 \mathrm{~mm}$ ).

\section{Diffusion-Relaxation Combined Imaging of the Placenta (DECIDE)}

The DECIDE protocol combines diffusion weighted imaging (acquired at $7 \mathrm{~b}$-values), and $\mathrm{T} 2$ imaging (10 echo times), and fits a three-compartment model to the change in per-voxel image signal at each acquired combination of $b$-value and echo time. The method is summarised in Figure 1. The DECIDE method assumes that within the placenta a voxel is made up of three compartments: fetal blood, maternal blood and tissue (trophoblastic and myometrium) with each of these compartments having their own perfusion volume fraction, diffusivity (D) and T2 relaxation rate. The model fitted to MR signal has nine parameters, four of which are known and fixed, thus five fitted parameters describe individual placental function: 1) the fraction of moving maternal blood (v), 2) the fraction of moving fetal blood (f), 3) diffusivity (D) of blood movement in maternal spaces and tissue, 4) the pseudodiffusivity $\left(D^{*}\right)$ of faster blood movement (relative to $D$ ), seen in the fetal blood, 5) feto-placental T2 relaxation time, from which the feto-placental blood oxygen saturation is estimated for the fetal compartment (Portnoy et al., 2017).

Model parameters are fitted using non-linear least squares as previously described (Melbourne et al., 2019). 
The DECIDE procedure, and parameters derived from it are outlined in Figure 1.

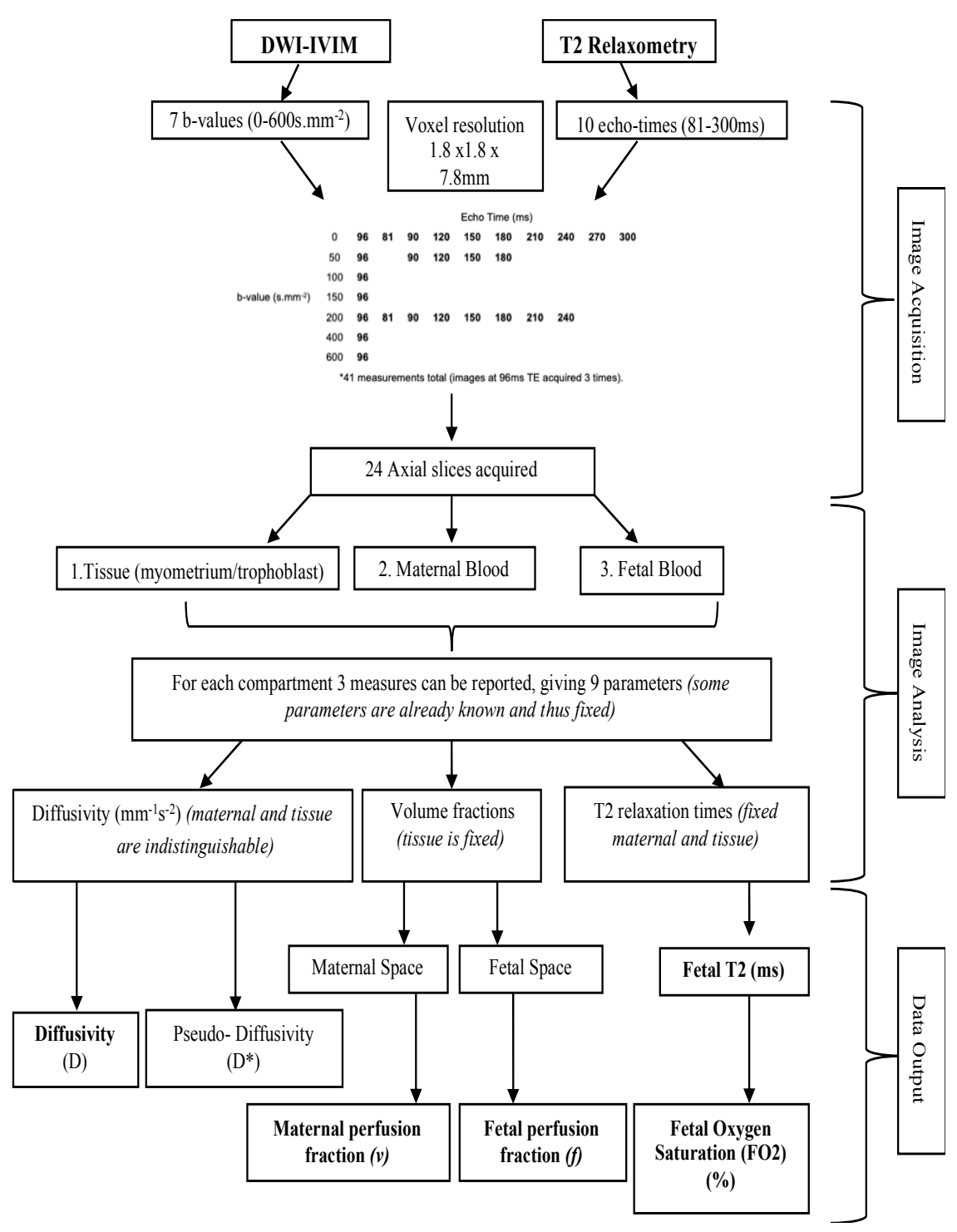

Figure 1: A flow chart summarising the steps involved in the DECIDE protocol, and the maternal and fetal parameters derived from imaging.

MRI Analysis

PC-MRI analysis

Blood flow was quantified, using the PC-MRI images acquired from the right and left internal iliac arteries in supine and LLD positions and the fetal umbilical vein. Using Syngo $\mathrm{Via}^{\mathrm{R}}$ (Siemens) 
software, vessels of interest were identified. A circular region of interest (ROI) was manually created around the lumen of each vessel. This ROI was then superimposed on all 20 slices that were taken from the same level over 16 cardiac cycles. Each slice was manually checked to ensure that the ROI accurately encompassed the vessel of interest, as the software attempted to accommodate the pulsatility of the vessel over the cardiac cycles. From this, Syngo $\mathrm{Via}^{\mathrm{R}}$ was used to calculate the vessel net forward volume (L). By multiplying participant HR (bpm) by net forward volume, volume flow in $\mathrm{mL} /$ minute was calculated (Humphries et al., 2019). Intra-observer measurements were compared between the initial analysis and a subsequent repeat at least 2 weeks later, using a t-test to determine if the difference between measurements was equivilant to zero. The first measurement was used for the analysis of left lateral versus supine outcomes

\section{DECIDE Analysis}

The placental volume was manually segmented by one author (A.C.) and verified by a second author (S. C.) using the images acquired with $b$-value $=0 \mathrm{~s} / \mathrm{mm}^{2}$, and lowest echo time $=96 \mathrm{~ms}$. Analysis of the DECIDE parameters within these masked regions was conducted as described previously by Melbourne et al (2019) (Melbourne et al., 2019). Briefly, the segmentations were of the entire placenta and as the ROIs were consistent between left lateral and supine, there was no need to match the regions. Figure 2 shows an example of a placental segmentation and DECIDE parameters determined as a parametric map in a single slice of that placental volume in a single participant.

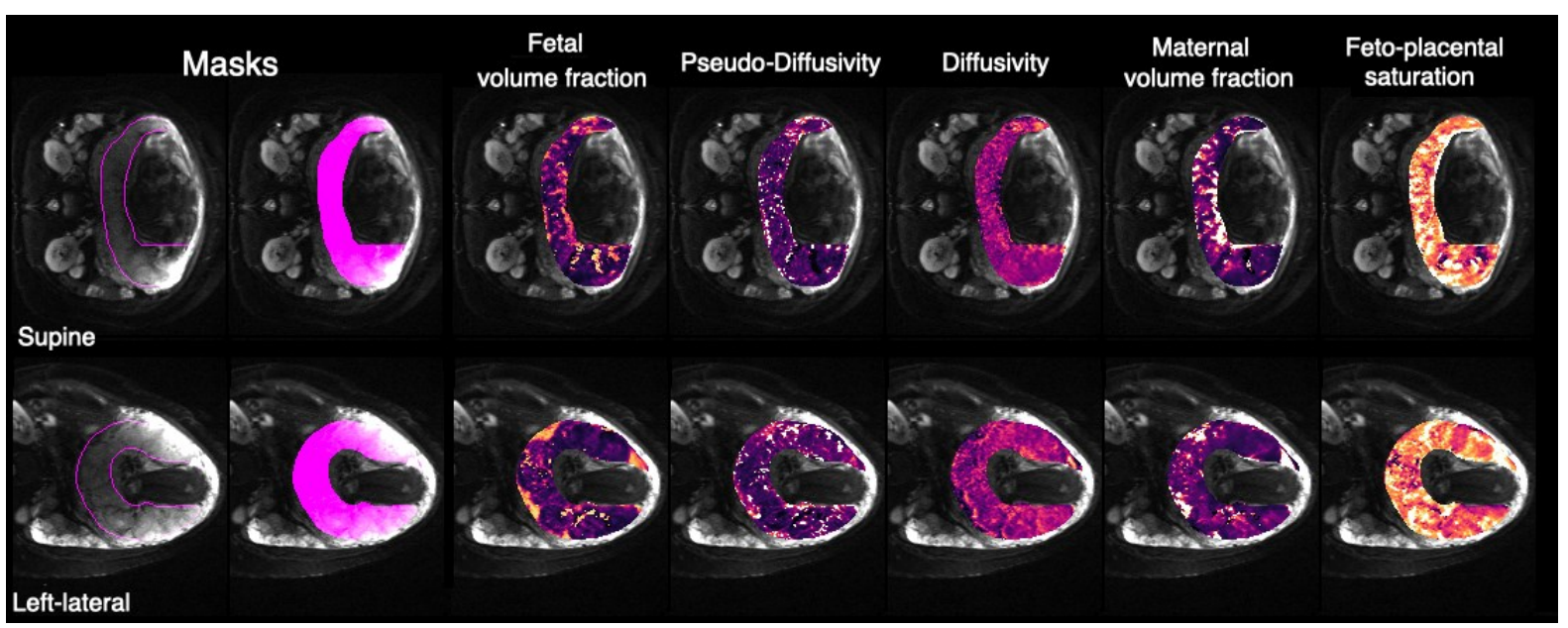

Figure 2: An example of placental segmentation (left panels) and DECIDE parameters derived from imaging in supine (top) and left lateral (bottom) positions. All images are oriented in the same way (with image oriented to show the participant on the left side) to allow visualisation of the change placental presentation between imaged positions. 
Additional Parameters derived from DECIDE and PC-MRI imaging

We also defined two additional physiological markers of placental function to indicate fetal oxygen flux, which may be more indicative of oxygen delivery from the placenta to the fetus than the original DECIDE parameters. Flux is a measurement of the transfer of substance through a surface and is related to the diffusivity of the substance and the net concentration gradient across the surface. These are represented by the extra-cellular diffusivity, measured by diffusion imaging where we assume that free oxygen has a proportional diffusivity to that of free water and the oxygen saturation difference between maternal and fetal blood compartments.Two flux indices we defined were calculated from parameters in the PC-MRI and DECIDE methods;

Placental Flux - representing oxygen movement within the placenta:

$$
\text { Placental Flux }=\text { Diffusivity }\left(\mathrm{mm}^{2} \mathrm{~s}^{-1}\right) x \text { Fetal Oxygen saturation }(\%)
$$

This flux definition assumes that water diffusivity is proportional to free oxygen diffusivity.

Delivery Flux -representing the rate of movement of oxygenated blood in the umbilical vein:

$$
\text { Delivery Flux }=\text { Fetal oxygen saturation }(\%) \text { x umbilical vein flow }(\mathrm{mL} / \mathrm{min})
$$

This flux definition assumes that blood flow is proportional to erythrocyte flow.

\section{Statistical Analysis}

Demographic data were expressed as the mean and standard deviation. Paired t-tests were used to compare blood flow (PC MRI) and placental (DECIDE) results between the two positions.

Results

Participant demographics and birth outcomes

Twenty-two women were recruited over 8 months for this study. Of these, 20 completed scans in both supine and LLD positions. Only results from the 20 completed protocols are reported. None of the 20 women smoked cigarettes. The remaining 2 women were excluded as they were unable to lie supine for the entire sequence and thus did not have adequate data for comparison between positions. The pregnancy outcomes are presented Table 1 .

All neonates were normally formed and of a healthy birth weight $>10^{\text {th }}$ customised percentile. All neonates were born in good condition with the range of Apgar scores being 7 to 10 at 1 and 5 minutes. 
Table 1: Participant demographics and birth outcomes.

\begin{tabular}{|c|c|c|}
\hline & & Participants $(n=20)$ \\
\hline Maternal age at MRI (mean (SD) age in years) & & $32( \pm 4.1)$ \\
\hline Gestational age at MRI (range in weeks + days) & & $34+0-37+5$ \\
\hline Pre-pregnancy BMI mean $\mathrm{kg} / \mathrm{m}^{2}$ (SD) & & $23( \pm 1.9)$ \\
\hline \multirow[t]{2}{*}{ Gravidity } & 1 & 14 \\
\hline & $>1$ & 6 \\
\hline \multirow[t]{2}{*}{ Parity } & 0 & 17 \\
\hline & 1 & 3 \\
\hline Birth weight mean (SD) (grams) & & $3415( \pm 497)$ \\
\hline Gestational age at delivery (range weeks + days) & & $37+1-41+6$ \\
\hline \multirow[t]{2}{*}{ Sex of fetus } & Male & 11 \\
\hline & Female & 9 \\
\hline APGAR SCORE at 5 minutes (Range) & & $7-10$ \\
\hline
\end{tabular}

MRI Analysis

A summary of the impact of maternal position on MRI-derived maternal and fetal haemodynamics, as well as placental function via DECIDE, is given in Table 2. 
Table 2: The effect of maternal position on blood flow measures derived from PC-MRI and placental function determined by a DECIDE analysis.

\begin{tabular}{|c|c|c|c|c|c|c|}
\hline & LLD & Supine & $\begin{array}{c}\text { Absolute } \\
\text { difference in } \\
\text { supine } \\
\text { compared to } \\
\text { LLD } \\
\text { (95\% CI) }\end{array}$ & p-value & $\begin{array}{l}\text { Percentage } \\
\text { difference in } \\
\text { supine } \\
\text { compared to } \\
\text { LLD } \\
(95 \% \text { CI })\end{array}$ & p-value \\
\hline \multicolumn{7}{|c|}{ PC-MRI ANALYSIS } \\
\hline $\begin{array}{l}\text { Right internal iliac } \\
\text { artery }(\mathrm{ml} / \mathrm{min})\end{array}$ & $353 \pm 123$ & $281 \pm 102$ & $-72(-109,-34)$ & 0.0007 & $\begin{array}{c}-19.0(-29.3 \\
-8.7)\end{array}$ & 0.0011 \\
\hline $\begin{array}{l}\text { Left internal iliac } \\
\operatorname{artery}(\mathrm{ml} / \mathrm{min})\end{array}$ & $400 \pm 86$ & $290 \pm 102$ & $\begin{array}{c}-110(-153,- \\
66)\end{array}$ & $<0.0001$ & $\begin{array}{c}-27.0(-37.1 \\
-16.8)\end{array}$ & $<0.0001$ \\
\hline $\begin{array}{c}\text { Total internal iliac } \\
\text { artery (ml/min) }\end{array}$ & $754 \pm 180$ & $572 \pm 177$ & $\begin{array}{c}-182(-251,- \\
113)\end{array}$ & $<0.0001$ & $\begin{array}{c}-23.7(-32.3 \\
-15.1)\end{array}$ & $<0.0001$ \\
\hline $\begin{array}{c}\text { Umbilical vein } \\
\text { (ml/min) }\end{array}$ & $296 \pm 80$ & $263 \pm 68$ & $-33(-68,3)$ & 0.0680 & $\begin{array}{c}-8.4(-18.1 \\
1.3)\end{array}$ & 0.0867 \\
\hline \multicolumn{7}{|c|}{ DECIDE ANALYSIS } \\
\hline $\begin{array}{c}\text { Maternal perfusion } \\
\text { fraction (v)* }\end{array}$ & $0.238 \pm 0.068$ & $\begin{array}{c}0.254 \pm \\
0.064\end{array}$ & $\begin{array}{c}0.016(-0.001 \\
0.034)\end{array}$ & 0.0629 & $\begin{array}{c}9.0(0.4 \\
17.7)\end{array}$ & 0.0418 \\
\hline $\begin{array}{c}\text { Fetal perfusion } \\
\text { fraction }(f)^{*}\end{array}$ & $0.314 \pm 0.042$ & $\begin{array}{c}0.344 \pm \\
0.051\end{array}$ & $\begin{array}{c}0.028(0.004 \\
0.051)\end{array}$ & 0.0249 & $\begin{array}{c}9.6(1.5 \\
17.8)\end{array}$ & 0.0234 \\
\hline $\begin{array}{c}\text { Diffusivity }\left(\times 10^{-3}\right) \\
\left(\mathrm{mm}^{2} \mathrm{~s}^{-1}\right)\end{array}$ & $\begin{array}{c}1.59 \pm 0.13 \\
\times 10^{-3}\end{array}$ & $\begin{array}{c}1.55 \pm \\
0.20 \times 10^{-3}\end{array}$ & $\begin{array}{l}-0.03(-0.09 \\
0.20) \times 10^{-3}\end{array}$ & 0.2010 & $\begin{array}{c}-2.4(5.9,- \\
1.1)\end{array}$ & 0.1717 \\
\hline $\begin{array}{c}\text { Pseudo-Diffusivity } \\
\left(\mathrm{mm}^{2} \mathrm{~s}^{-1}\right)\end{array}$ & $0.058 \pm 0.017$ & $\begin{array}{c}0.076 \pm \\
0.051\end{array}$ & $\begin{array}{c}0.018(-0.008 \\
0.043)\end{array}$ & 0.1603 & $\begin{array}{c}40.3(-6.6 \\
87.2)\end{array}$ & 0.0879 \\
\hline Fetal Blood T2 (ms) & $\begin{array}{c}135.48 \pm \\
21.54\end{array}$ & $\begin{array}{c}130.19 \pm \\
21.66\end{array}$ & $\begin{array}{c}-5.29(-14.6 \\
4.03)\end{array}$ & 0.2496 & $\begin{array}{c}-2.9(-9.5 \\
3.7)\end{array}$ & 0.3679 \\
\hline $\begin{array}{c}\text { Fetal oxygen } \\
\text { saturation }\left(\mathrm{FO}_{2}\right)(\%)\end{array}$ & $67.20 \pm 7.95$ & $\begin{array}{c}63.90 \pm \\
8.32\end{array}$ & $\begin{array}{c}-3.29(-6.77 \\
0.18)\end{array}$ & 0.0615 & $\begin{array}{c}-4.4(-9.4 \\
0.6)\end{array}$ & 0.0793 \\
\hline
\end{tabular}

This article is protected by copyright. All rights reserved. 
Results reported as mean $( \pm S D)$. *Perfusion fractions can be interpreted as percentages when multiplied by 100. LLD - left lateral decubitus

\section{Maternal internal iliac and fetal umbilical vein flow and the effect of position}

Highly significant reductions of $19.0 \%(\mathrm{p}=0.0011)$ and $27.0 \%(\mathrm{p}<0.0001)$ were found in the right and left internal iliac arterial flows respectively when the women were supine compared with being in LLD position. When right and left blood flows were combined (total internal iliac flow) a $23.7 \%$ decrease $(\mathrm{p}<0.0001)$ was seen when women lay supine compared to LLD. No significant differences in left and right internal iliac flows were found, indicating no dominant side. Umbilical venous (UV) flow was not significantly reduced $(8.4 \%, \mathrm{p}=0.0867)$ when women lay supine compared to LLD $(296 \pm 80 \mathrm{~mL} / \mathrm{min}$ LLD to $263 \pm 68 \mathrm{~mL} / \mathrm{min}$ supine). The results of changes in both maternal and fetal blood flow with maternal position are summarised in Table 2 .

\section{Effect of maternal position on placental perfusion and oxygen delivery (DECIDE Analysis)}

Diffusivity measures: Diffusivity (D), reduced 2.4\% ( $\mathrm{p}=0.17)$ when supine compared to LLD $\left(0.00155 \pm 0.0002\right.$ vs $\left.0.00159 \pm 0.00013 \mathrm{~mm}^{2} \mathrm{~s}^{-1}\right)$. Pseudo-diffusivity (D*) was not significantly increased $(40.3 \%, \mathrm{p}=0.0879)$ when women moved supine $(0.0580 \pm 0.017$ LLD vs $0.0760 \pm 0.051$ $\mathrm{mm}^{2} \mathrm{~s}^{-1}$ supine).

Perfusion fractions: Maternal perfusion fraction (v) showed a significant difference when women were in the supine position; with an average increase of $9.0 \%(\mathrm{p}=0.0418)$ for $v(0.238 \pm 0.068$ LLD vs $0.254 \pm 0.064$ supine). The fetal perfusion fraction $(f)$ showed a significant increase of $9.6 \%$ ( $\mathrm{p}=0.0234)$ for $f(0.314 \pm 0.042 \mathrm{LDD}$ vs $0.344 \pm 0.051$ supine). Regardless of maternal position, significant relationships were found between perfusion fraction and PC-MRI blood flow in maternal arteries for $v$ and the fetal umbilical vein for $f$. On the maternal side there was a significant correlation between $v$ and PC-MRI derived total maternal iliac blood flow $(\mathrm{r}=0.51, \mathrm{p}=0.001)$, no significant correlation existed with $v$ and fetal umbilical PC-MRI $(\mathrm{r}=0.24, \mathrm{p}=0.14)$. There was also a significant correlation between $f$ and PC-MRI derived umbilical venous flow $(\mathrm{r}=-0.36, \mathrm{p}=0.035)$, and no significant relationship between $f$ and internal iliac flow $(\mathrm{r}=0.29, \mathrm{p}=0.063)$.

Fetal T2 and fetal oxygen saturation: Parameters relating to fetal blood oxygen saturation in the fetal region of the placenta, were found to show no statistically significant changes between supine and 
LLD positions. The T2 relaxation rate of the fetal blood was $2.9 \%$ lower (135.48 $\pm 21.54 \mathrm{~ms}$ LLD to $130.19 \pm 21.66 \mathrm{~ms}(\mathrm{p}=0.23679)$ when in the supine position. Fetal oxygen saturation $\left(\mathrm{FO}_{2}\right)$, calculated from these T2 measures, was $4.4 \%$ lower $[67.20 \pm 7.95 \%$ LLD to $63.90 \pm 8.32 \%(p=0.0793)]$ when women lay supine.

Placental flux and Delivery flux: Placental flux showed a statistically significant difference between supine and left lateral positions. The placental flux index, the product of $D\left(\mathrm{~mm}^{2} \mathrm{~s}^{-1}\right)$ and $\mathrm{FO}_{2}$, as a measure of oxygen movement across the placenta reduced by $6.2 \%(p=0.0380)$ when women were supine compared to $L L D(0.000976 \pm 0.00021$ supine vs $0.001064 \pm 0.00020$ LLD). The delivery flux, the product of $\mathrm{UV}$ flow and $\mathrm{FO}_{2}$ described oxygen delivery from the fetal compartment of the placenta to the fetus. This reduction did not reach statistical significance $(11.2 \%, p=0.0597)$ when women lay supine compared to LLD (from $199.38 \pm 60.70$ LLD to $168.62 \pm 48.22$ supine).

A summary of DECIDE findings, and their relationship with placental function is displayed graphically in Figure 3. 


\section{Summary of maternal-fetal interaction and the effect of position}

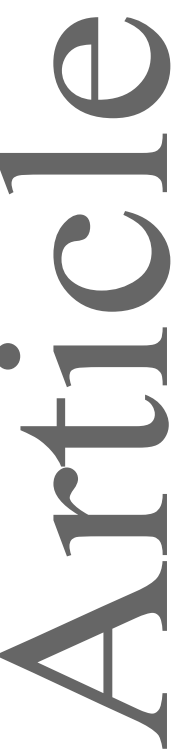

\section{Left Lateral Decubitus Supine}
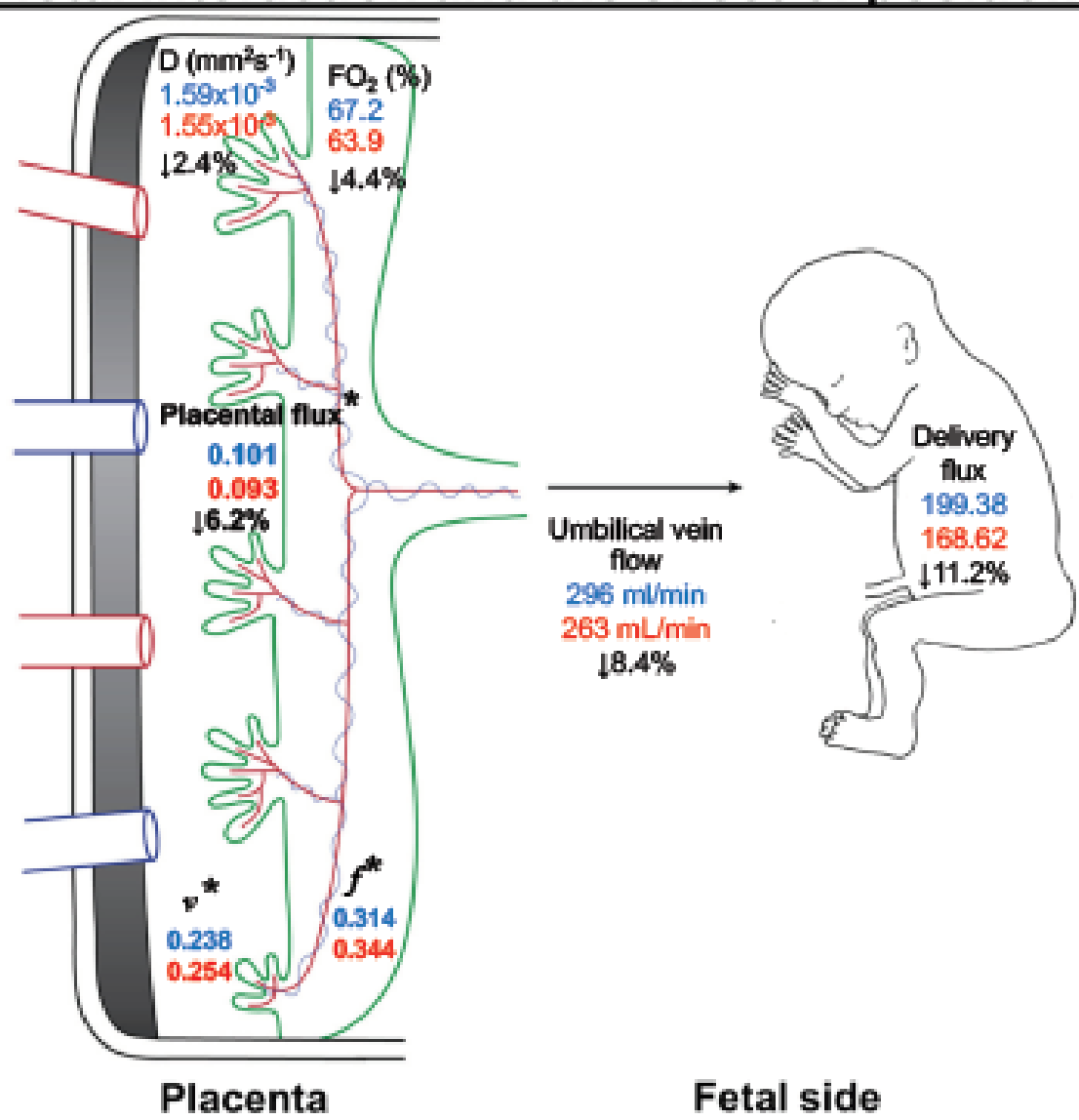

Maternal side

Placenta

Fetal side

Figure 3 The Summary Effect of Maternal Position on uteroplacental blood flow and oxygen delivery. results which reached statistical significance are shown with an asterix

\section{Discussion}

This study has shown the effect of maternal position on utero-placental and feto- placental blood flow and oxygenation, in healthy late gestation pregnancy. When lying supine compared to left lateral decubitus (LLD) there were significant reductions in utero-placental blood flow (as reflected in the internal iliac arteries) and oxygen transfer or flux in the placenta and to the fetus. The fetal and fetoplacental response to an acute reduction in oxygen in healthy late gestation pregnancy has not been demonstrated previously where subjects served as their own controls. This protocol is as standardised an investigative paradigm as possible given the constraints of MRI.

This study was performed in late gestation (34-38 weeks), a period when most unexplained stillbirths occur. Maternal position was found to be associated with large changes in the internal iliac blood 
flow. It was not possible to directly image and resolve the uterine arteries, due to voxel resolution and variable anatomy. The internal iliac arteries branch into the uterine arteries which are the principal vessels supplying oxygen and nutrients to the placenta. The consequence of the positional effects was a reduction of oxygen transfer across the placenta to the fetus. This is reflected in reduced fetal oxygen saturation (FO2) in the placenta and blood flow to the fetus (summary figure, Figure 3).

The current study has provided a physiological explanation for the previously discussed epidemiological studies which found a correlation between supine sleep position in late gestation pregnancy and an increased risk of stillbirth. The current study supports and expands the findings of Humphries et al. (2019) (Humphries et al., 2019), where a significant reduction in maternal abdominal aortic blood flow (32.3\%) was identified when mothers lay supine compared to left lateral decubitus (LLD) in late gestation healthy pregnancy. Significant findings in the present study show that when a healthy pregnant woman is put under the physiological stress of lying supine, compared to LLD, the effect is a clear reduction in blood flow in the utero-placental and feto-placental units.

Humphries et al. (2019) also reported a 16.4\% reduction in maternal cardiac output using PC-MRI, in addition to a $32.3 \%$ reduction in maternal abdominal aortic flow (Humphries et al., 2019). Assessments in the present study have shown that this leads to a significant $24.1 \%$ reduction in the total maternal internal iliac arterial flow. A smaller study investigating the effects of exercise on uterine blood flow using Doppler ultrasound reported a 34\% reduction in right ascending uterine artery volume flow when women in late gestation were in the supine compared with left lateral position (Jeffreys et al., 2006). In a study using transvaginal ultrasound, volume flow in the left ascending uterine artery was found to be a mean of $342 \mathrm{ml} / \mathrm{min}$ in late pregnancy (Thaler et al., 1990), and similar results were found by Palmer in a study of 18 women where at 36 week's gestation, unilateral uterine artery blood flow was a mean of $312 \pm 22 \mathrm{~mL} / \mathrm{min}$ (Palmer et al., 1992). Our upstream MRI estimates of blood flow in the internal iliac arteries are consistent with these results.

In the current study, using PC MRI, it was observed that the umbilical vein (UV) blood flow reduced from a mean $296 \mathrm{~mL} / \mathrm{min}$ when LLD to $264 \mathrm{~mL} / \mathrm{min}$ when lying supine ( $8.4 \%$ decrease). Whilst this result was not statistically significant it was consistent with previous reports of UV blood flow using PC MRI of $232 \mathrm{~mL} / \mathrm{min}$, (position not stated) (Krishnamurthy et al., 2018) and $356 \mathrm{~mL} / \mathrm{min}$ in LLD (Sussman et al., 2019). Both of these studies found strong interobserver correlation coefficients demonstrating the reliability of PC MRI for measuring UV blood flow. It has been observed in sheep, that an occlusion above $90 \%$ in the uterine arteries was required to induce any effect on the UV blood flow (Gu et al., 1985). Although in this study we reported a much smaller reduction in internal iliac blood flow when changing from LLD to supine positions, the $24 \%$ significant reduction in total iliac flow was accompanied by an $11 \%$ drop in umbilical venous flow. In healthy pregnancy, UV blood 
flow may only drop once a threshold reduction in maternal flow has been met. This is also supported by a lack of a significant relationship between internal iliac and UV blood flows measured in this study $(r=0.017, p=0.92)$. These findings together are suggestive of a non-linear relationship between maternal and UV blood flow. If a pregnancy had complications such as FGR, one might expect the UV flow to drop earlier with a lower maternal blood flow threshold, due to an already stressed system (Jensen et al., 1991).

The reduction in blood flow to the placenta related to maternal position was expected to be associated with hypoxia in the fetoplacental unit and this has been confirmed using these MRI techniques. The DECIDE MRI technique used in this study had only previously been applied in a feasibility study of six pregnant women in mid-gestation (26-30 weeks) (Melbourne et al., 2019) and in early onset FGR (Aughwane et al., 2020) and this is the first demonstration of its use in late gestation. Studies in fetal sheep have shown that a reduction in uterine blood flow leads to reduced fetal oxygen delivery and redistribution of oxygenated fetal blood (Jensen et al., 1991). Inducing acute hypoxia in the fetal sheep has also been shown to increase resistance to blood flow in the UVs with no change in the resistance in the umbilical arteries or placenta (Paulick et al., 1990). It was speculated that this may enhance oxygen uptake by the umbilical venous circulation. A review of human ultrasound studies reported measures of umbilical venous blood flow consistent with those described by the DECIDE analysis (Najafzadeh \& Dickinson, 2012) and changes seen in umbilical venous flow or ductus venosus shunting in hypoxia reflect our findings (Tchirikov et al., 2006).

In aiming to provide an estimate of the effect of maternal position on the magnitude of placental oxygen transfer reduction when supine, we developed the concept of placental flux. We defined this as the product of Diffusivity (D) and $\mathrm{FO}_{2}$ to provide an indication of oxygen transfer across the placenta. This was seen to significantly reduce by $6.2 \%$ when women took up the supine position compared to LLD. Placental flux, and its distinct reduction when supine, supports the hypothesis that in this physiologically stressed position, less oxygen can diffuse from the maternal to the fetal compartment within the placenta.

The DECIDE analysis as described also permitted an estimate of oxygen delivery to the fetus which we termed delivery flux. Delivery flux was derived from the product of UV flow and $\mathrm{FO}_{2}$. The reduction in this index seen when the women were supine compared with being LLD (11.2\%) was not found to be statistically significant. Further studies will be needed to determine if this was an issue of power of the current study. The index was derived from DECIDE and PC MRI parameters and as such there are no direct comparators in the literature. The aim of this index was to provide an indication of the oxygen delivery rate to the fetus from the placenta, and how it was affected by maternal position changes. 
The results of this study provide further evidence that even short periods in the supine position (2030minutes) act as a stressor to the fetus. These results are consistent with the previously reported change to fetal behavioural state $1 \mathrm{~F}$ when women assumed a supine position in late pregnancy (Stone et al., 2017). Studies utilising Doppler ultrasound have shown that the supine lying position is a sufficient physiological stress to induce the so-called brain sparing compensatory mechanism by the fetus.(Khatib et al.,2014)) Significant reductions in placental flux (6.2\%), and delivery flux (11.2\%), as well as a non statistically significant but physiologically relevant reduction in FO2 (4.4\%) in our results would suggest that even in healthy late gestation pregnancy, the reduction in umbilical venous flow that is thought to facilitate increased fetal oxygen uptake by matching flow to intervillous oxygen delivery (Talbert \& Sebire, 2004) is insufficient to completely compensate for the effects of the supine position.

The response of the fetus to the effect of maternal change from LLD to a supine position is likely to be rapid. In in vitro studies with perfused human placental lobules, it was shown that the onset of hypoxic vasoconstriction was observed within 5 minutes of reduced oxygen delivery and by 10 minutes of reduced oxygen delivery, a stable response was reached (Jakoubek et al., 2006). Similar time periods were involved in in vivo human Doppler studies (Khatib et al., 2014). This would suggest that in the current MRI study, at the time of data acquisition, a compensated fetus was imaged. There was an average of 15 minutes between initiation of a supine or LLD position and collection of images used for analysis, due to movement of the participant to and from the MR bore, and preliminary scout imaging. This time period is estimated to be sufficient to induce a hypoxic fetal compensatory response.

\section{Strengths}

Each woman who took part in this study completed scans in supine and LLD positions, and therefore acted as her own control. In addition the order of maternal positioning was randomly determined and all scans were completed under standardised conditions. There are correlations and consistency between PC-MRI blood flow and DECIDE results in maternal and fetal metrics, separately, which support the validity of the DECIDE method to separate the placenta into maternal and fetal compartments. PC MRI has been shown to be reliable for Syngo Via ${ }^{\mathrm{R}}$ (Siemens) analysis and vessel selection. Previous studies have reported strong interobserver reproducibility for PC MRI in other maternal vessels (Humphries et al., 2019). Strong interobserver reliability has also been reported for PC MRI analysis of UV flow (Krishnamurthy et al., 2018; Sussman et al., 2019).

The results presented in this study show a strong association between the effect of position and measures of oxygenation despite a moderate cohort size. In addition, this study is unique in its 
approach to investigating normal human pregnancy in late gestation MRI studies, as we assess the impact of position on placental parameters, allowing a direct comparison of maternal and fetal parameters in the same pregnancies.

\section{Limitations}

Motion artefacts and distortion of images are a commonly reported issue and complication of an MRI scan (Derwig et al., 2013; Siauve et al., 2015). This is only made more challenging during pregnancy. The present study was not immune to these challenges. Acquisition of the UV PC MRI was the most at risk of distortion, and often required repeated imaging of the vessel, adding to total scan time. The internal iliac arteries were only at risk of maternal movement, which was controlled for by breath holding during acquisition of all PC MRI. When acquiring the placenta images, maternal motion was more of a problem than fetal activity. Nevertheless, any motion that could have potentially affected the images used for DECIDE analysis was corrected retrospectively (Flouri et al., 2019). Where obvious large motion occurred during the DECIDE protocol, these images were repeated. In the event, for both PC MRI and DECIDE imaging in the 20 cases reported, no images were rejected due to motion artefact.

The current lack of MRI compatible fetal heart rate monitors prevented the ability to gain beat to beat fetal HR information during the MRI, as was done for the assessment of the maternal HR and blood pressure. Fetal HR was manually gated at $150 \mathrm{bpm}$ for both supine and the LLD positions. Controversy surrounds the discussion of how much fetal HR changes in different maternal positions. Tamás et al. (Tamás et al., 2007) reported a significant increase in fetal HR when supine compared to LLD, assessed using non-stress test (NST), of $139.3 \pm 8.1 \mathrm{bpm}$ supine and $134.4 \pm 15.8 \mathrm{bpm}$ LLD. NST is an assessment of fetal welfare used in late gestation, focusing on fetal HR activity using electronic monitoring. In contrast, Jeffreys et al. (2006) found, using Doppler ultrasound, no change between LLD and supine position fetal HR (Jeffreys et al., 2006).

The arcuate and radial arteries which in turn supply the spiral arterioles are too small to be seen by current MRI techniques. Due to requiring the capture of the entire placenta, in our MRI the field of view, voxel thickness, and resolution meant the uterine arteries could not be identified, and thus the internal iliac arteries were measured. However, it has been shown in this study and illustrated in the functional model, that by combining with the DECIDE method, we were able to assess the intervillous space in the placenta and specifically the activity of oxygen. The added scan time, cost, lack of reliability of the uterine arteries, would not provide new information, in comparison to what would be gained from the assessment of the oxygen itself within the placenta. 
The sample size for this study was pragmatic in nature due to fact that this work is novel and thus preexisting data to make power calculations was unavailable, nor is it known what a clinically relevant change in these parameters is. Previous MRI work by members of the authorship group on other outcomes has used samples in the order of 10-12 subjects, thus a sample size of 20 subjects was considered to be in the expected order of magnitude to be relevant. This study now provides baseline data that can be used to estimate sample size for studies measuring similar parameters

\section{Conclusion}

In this novel study, it has been found that the effect of maternal supine position in late gestation healthy pregnancy is a reduction in not only maternal internal iliac arterial blood flow (the principal blood flow to the uterus), but also oxygen diffusion across the placenta which we termed placental flux. The delivery flux, relating umbilical blood flow to the fetal oxygen saturation was not significantly reduced in this study although UV flow reduction was observed in the supine position. This observation is likely due to vasoconstriction within the placenta and a fetal chemoreflex response, suggesting that the healthy fetus adapted to the positional hypoxia. The effect of the supine position in vulnerable growth restricted pregnancies may be less well tolerated.

It is speculated that our observed $11.2 \%$ reduction in delivery flux across the placenta, whilst tolerated in healthy fetuses, is potentially a major stressor in the vulnerable fetus such as one with growth restriction (Warland \& Mitchell, 2014). The data presented in this study show that in healthy late gestation pregnancy, simply by encouraging women to lie on their left side in pregnancy would prevent a $6.2 \%$ reduction in oxygen delivery across the placenta.

\section{Additional Information}

All data in a non identifying format are securely stored at the Faculty of Medical and Health Sciences, The University of Auckland. The data are available upon request. The basic data has been collated in Excel $^{\mathrm{R}}$.

The authors declare no competing interests.

Author contributions

Conceptualisation of the study PS, AC, AMi, AMe, AD

Data curation was performed by JT and SC 
Formal analysis was undertaken by JT, SC with advice from AC, AMe,

Funding acquisition was by PS and AC.

The investigation both clinical and of the MRI data was by SC, AC, AMe.

The methodology included both clinical and MRI analytical components and was contributed to by SC, AC, PS, JT, AMe, DF, RA.

The project was administered by PS, Ami.

The resources were provided by the University of Auckland.

Software was proprietary and its use supervised by JT.

Supervision overall was by PS, Ami and AC.

Writing of the original draft was by SC, PS JT and AC, with subsequent contributions from all other authors, DF, RA, AD, AMe.

Writing for the response to reviewers was from all authors.

The final version of the manuscript was approved by all authors, who agree to be accountable for all aspects of the work.

It is confirmed that all authors do qualify for authorship.

Funding

This project was funded by Cure Kids (Grant number 3720229) and the Auckland Medical Research Foundation (Grant number 1118010). AM was supported by the Wellcome Trust (210182/Z/18/Z, 101957/Z/13/Z) and EPSRC (NS/A000027/1). ALD is supported by the National Institute for Health Research University College London Hospitals Biomedical Research Centre.

Acknowledgments

We acknowledge Ms Anna Lydon and the team at CAMRI, University of Auckland and thank the women who participated in this study. 
References

Acharya G, Wilsgaard T, Rosvold Berntsen GK, Maltau JM, Kiserud T. (2005). Reference ranges for serial measurements of umbilical artery Doppler indices in the second half of pregnancy. $\mathrm{Am}$ J Obstet Gynecol 192, 937-944.

Aughwane R, Ingram E, Johnstone ED, Salomon LJ, David AL \& Melbourne A. (2020). Placental MRI and its application to fetal intervention. Prenat Diagn 40, 38-48.

Aughwane R, Mufti N, Flouri D, Maksym K, Spencer R, Sokolska M, Kendall G, Atkinson D, Bainbridge A, Deprest J, Vercauteren T, Ourselin S, David AL, Melbourne A. (2020). MRI Measurement of Placental Perfusion and Oxygen Saturation in Early Onset Fetal Growth Restriction. BJOG. doi:10.1111/1471-0528.16387

Avni R, Golani O, Akselrod-Ballin A, Cohen Y, Biton I, Garbow JR \& Neeman M. (2016). MR imaging-derived oxygen-hemoglobin dissociation curves and fetal-placental oxygenhemoglobin affinities. Radiol 280, 68-77.

Bihan DL, Breton; E, Lallemand; D, Aubin; M-L, Vignaud; J \& Laval-Jeantet M. (1988). Separation of Diffusion and Perfusion in Intravoxel Incoherent Motion MR Imaging Radiol 168, 497505 .

Capuani S, Guerreri M, Antonelli A, Bernardo S, Porpora MG, Giancotti A, Catalano C \& Manganaro L. (2017). Diffusion and perfusion quantified by Magnetic Resonance Imaging are markers of human placenta development in normal pregnancy. Placenta 58, 33-39.

Carter A. (2009). Evolution of factors affecting placental oxygen transfer. Placenta 30, 19-25.

Chan A, King J, Flenady V, Haslam R \& Tudehope D. (2004). Classification of perinatal deaths: development of the Australian and New Zealand classifications. J Paediatr Child Health 40, 340-347.

Cronin RS, Wilson J, Gordon A, Li M, Culling VM, Raynes-Greenow CH, et al. (2020) 
Associations between symptoms of sleepdisordered breathing and maternal sleep patterns with late stillbirth: Findings from an individual participant data meta-analysis. PLoS ONE 15(3):e0230861.

Cronin RS, Li M, Thompson JMD, Gordon A, Raynes-Greenow CH, Heazell AEP, Stacey T, Culling VM, Bowring V, Anderson NH, O'Brien LM, Mitchell EA, Askie LM \& McCowan LME. (2019). An Individual Participant Data Meta-analysis of Maternal Going-to-Sleep Position, Interactions with Fetal Vulnerability, and the Risk of Late Stillbirth. E Clin Med 10, 49-57.

Derwig I, Lythgoe D, Barker G, Poon L, Gowland P, Yeung R, Zelaya F \& Nicolaides K. (2013). Association of placental perfusion, as assessed by magnetic resonance imaging and uterine artery Doppler ultrasound, and its relationship to pregnancy outcome. Placenta 34, 885-891.

Flenady V, Wojcieszek AM, Middleton P, Ellwood D, Erwich JJ, Coory M, Khong TY, Silver RM, Smith GC, Boyle FM, Lawn JE, Blencowe H, Leisher SH, Gross MM, Horey D, Farrales L, Bloomfield F, McCowan L, Brown SJ, Joseph KS, Zeitlin J, Reinebrant HE, Ravaldi C, Vannacci A, Cassidy J, Cassidy P, Farquhar C, Wallace E, Siassakos D, Heazell AE, Storey C, Sadler L, Petersen S, Frøen JF, Goldenberg RL. (2016). Stillbirths: recall to action in highincome countries. Lancet 387,691-702.

Flouri D, Owen D, Aughwane R, Mufti N, Maksym K, Sokolska M, Kendall G, Bainbridge A, Atkinson D, Vercauteren T, Ourselin S, David AL, Melbourne A. (2020). Improved Fetal Blood Oxygenation and Placental Estimated Measurements of Diffusion-Weighted MRI Using Data-Driven Bayesian Modeling. Magn Reson Med 83, 2160-2172.

Frias AE, Schabel MC, Roberts VH, Tudorica A, Grigsby PL, Oh KY \& Kroenke CD. (2015). Using dynamic contrast- enhanced MRI to quantitatively characterize maternal vascular organization in the primate placenta. Magn Reson Med 73, 1570-1578.

Gardosi J, Francis A, Turner S, Williams M. (2018). Customized growth charts: rationale, validation and clinical benefits. Am J Obstet Gynecol 218, S609-S618.

Ginosar Y, Gielchinsky Y, Nachmansson N, Hagai L, Shapiro J, Elchalal U \& Abramovitch R. (2018). BOLD-MRI demonstrates acute placental and fetal organ hypoperfusion with fetal brain sparing during hypercapnia. Placenta 63, 53-60. 
Gordon A, Raynes-Greenow C, Bond D, Morris J, Rawlinson W \& Jeffery H. (2015). Sleep Position, Fetal Growth Restriction, and Late-Pregnancy Stillbirth: The Sydney Stillbirth Study. Obstet Gynecol 125, 347-355.

Gu W, Jones C \& Parer J. (1985). Metabolic and cardiovascular effects on fetal sheep of sustained reduction of uterine blood flow. J Physiol 368, 109-129.

Heazell AEP, Li M, Budd J, Thompson JMD, Stacey T, Cronin RS, Martin B, Roberts D, Mitchell EA \& McCowan LME. (2018). Association between maternal sleep practices and late stillbirth findings from a stillbirth case- control study. BJOG 125, 254-262.

Huen I, Morris DM, Wright C, Parker GJ, Sibley CP, Johnstone ED \& Naish JH. (2013). R1 and R2* changes in the human placenta in response to maternal oxygen challenge. Magn Reson Med 70, 1427-1433.

Humphries A, Mirjalili SA, Tarr GP, Thompson JMD \& Stone P. (2019). The effect of supine positioning on maternal hemodynamics during late pregnancy. $J$ Maternal-Fetal Neonatal Med 32, 3923-3930.

Jakab A, Tuura RL, Kottke R, Ochsenbein- Kölble N, Natalucci G, Nguyen TD, Kellenberger C \& Scheer I. (2018). Microvascular perfusion of the placenta, developing fetal liver, and lungs assessed with intravoxel incoherent motion imaging. J Magn Reson Imaging 48, 214-225.

Jakoubek V, Bibova J \& Hampl V. (2006). Voltage-gated calcium channels mediate hypoxic vasoconstriction in the human placenta. Placenta 27, 1030-1033.

Jeffreys R, Stepanchak W, Lopez B, Hardis J \& Clapp III J. (2006). Uterine blood flow during supine rest and exercise after 28 weeks of gestation. BJOG 113, 1239-1247.

Jensen A, Roman C \& Rudolph A. (1991). Effects of reducing uterine blood flow on fetal blood flow distribution and oxygen delivery. $J$ Develop Physiol 15, 309.

Khatib N, Weiner Z, Beloosesky R, Vitner D \& Thaler I. (2014). The effect of maternal supine position on umbilical and cerebral blood flow indices. Europ J Obstet Gynecol Reprod Biol 175, $112-114$. 
Krishnamurthy U, Yadav BK, Jella PK, Haacke EM, Hernandez- Andrade E, Mody S, Yeo L, Hassan SS, Romero R \& Neelavalli J. (2018). Quantitative flow imaging in human umbilical vessels in utero using nongated 2d phase contrast MRI. J Magn Reson Imaging 48, 283-289.

Lawn JE, Blencoe H, Waiswa P, Amouzou A, Mathers C, Hogan D, Flenady V, Froen JF, Qureshi ZU, Calderwood C, Shiekh S, jassir FB, You D, McClure EM, Mathai M, Cousens S. (2016). Stillbirths: rates, risk factors, and acceleration towards 2030. Lancet 387, 587-603.

Lowe SA, Bowyer L, Lust K, McMahon LP, Morton MR, North RA, Paech M. Said JM. (2015). The SOMANZ Guideline for the Management of Hypertensive Disorders of Pregnancy 2014. Austr NZ J Obstet Gynaecol 55, 11-16.

Ludwig KD, Fain SB, Nguyen SM, Golos TG, Reeder SB, Bird IM, Shah DM, Wieben OE \& Johnson KM. (2019). Perfusion of the placenta assessed using arterial spin labeling and ferumoxytol dynamic contrast enhanced magnetic resonance imaging in the rhesus macaque. Magn Reson Med 81, 1964-1978.

Lum M, Tsiouris AJ. (2020). MRI safety considerations during pregnancy. Clinical Imaging 62, 6975.

Luo J, Turk EA, Bibbo C, Gagoski B, Roberts DJ, Vangel M, Tempany-Afdhal CM, Barnewolt C, Estroff J \& Palanisamy A. (2017). In vivo quantification of placental insufficiency by BOLD MRI: a human study. Scientific Reports 7, 1-10.

Manganaro L, Fierro F, Tomei A, La LB, Savelli S, Sollazzo P, Sergi ME, Vinci V, Ballesio L \& Marini M. (2010). MRI and DWI: feasibility of DWI and ADC maps in the evaluation of placental changes during gestation. Prenal Diagn 30, 1178-1184.

Melbourne A, Aughwane R, Sokolska M, Owen D, Kendall G, Flouri D, Bainbridge A, Atkinson D, Deprest J \& Vercauteren T. (2019). Separating fetal and maternal placenta circulations using multiparametric MRI. Magn Reson Med 81, 350-361. 
Ministry of Health. (2014). Screening, Diagnosis and Management of Gestational Diabetes in New Zealand: A clinical practice guideline. Wellington: Ministry of Health. ISBN: 978-0-47844460-5 (online)

Moore RJ, Strachan BK, Tyler DJ, Duncan KR, Baker PN, Worthington BS, Johnson IR \& Gowland PA. (2000). In utero perfusing fraction maps in normal and growth restricted pregnancy measured using IVIM echo-planar MRI. Placenta 21, 726-732.

Najafzadeh A \& Dickinson JE. (2012). Umbilical venous blood flow and its measurement in the human fetus. J Clin Ultrasound 40, 502-511.

Palmer SK, Zamudio S, Coffin C, Parker S, Stamm E \& Moore LG. (1992). Quantitative estimation of human uterine artery blood flow and pelvic blood flow redistribution in pregnancy. Obstet Gynecol 80, 1000-1006.

Paulick R, Meyers R, Rudolph C \& Rudolph A. (1990). Venous responses to hypoxemia in the fetal lamb. J Develop Physiol 14, 81-88.

Perinatal and Maternal Morality Review Committee (PMMRC). (2018). Twelfth Annual Report of the Perinatal and Maternal Morality Review Committee. Wellington: Healthy Quality and Safety Commission, Wellington NZ. ISBN 978-1-98-859904-5. https://www.hqsc.govt.nz/ourprogrammes/mrc/pmmrc accessed 11 June 2020

Portnoy S, Osmond M, Zhu MY, Seed M, Sled JG \& Macgowan CK. (2017). Relaxation properties of human umbilical cord blood at 1.5 Tesla. Magn Reson Med 77, 1678-1690.

Reinebrant HE, Leisher SH, Coory M, Henry S, Wojcieszek AM, Gardener G, Lourie R, Ellwood D, Teoh Z, Allanson E, BlencoweH, Draper ES, Erwich JJ, Frøen JF, Gardosi J, Gold K, Gordijn S, Gordon A, Heazell AEP, Khong TY, Korteweg F, Lawn JE, McClure EM, Oats J, PattinsonR, Pettersson K, Siassakos D, Silver RM, Smith G, Tuncalp O, Flenady V. (2018). Making stillbirths visible: a systematic review of globally reported causes ofstillbirth. BJOG $125,212-224$.

Richardson BS. (1989). Fetal Adaptive Responses to Asphyxia. Clin Perinatol. 16, 595-611.

This article is protected by copyright. All rights reserved. 
Schabel MC, Roberts VH, Lo JO, Platt S, Grant KA, Frias AE \& Kroenke CD. (2016). Functional imaging of the nonhuman primate Placenta with endogenous blood oxygen level-dependent contrast. Magn Reson Med 76, 1551-1562.

Shao X, Liu D, Martin T, Chanlaw T, Devaskar SU, Janzen C, Murphy AM, Margolis D, Sung K \& Wang DJ. (2018). Measuring human placental blood flow with multidelay 3D GRASE pseudocontinuous arterial spin labeling at 3T. J Magn Reson Imaging 47, 1667-1676.

Siauve N, Chalouhi GE, Deloison B, Alison M, Clement O, Ville Y \& Salomon LJ. (2015). Functional imaging of the human placenta with magnetic resonance. Am J Obstet Gynecol 213, S103-114.

Siauve N, Hayot PH, Deloison B, Chalouhi GE, Alison M, Balvay D, Bussières L, Clément O \& Salomon LJ. (2019). Assessment of human placental perfusion by intravoxel incoherent motion MR imaging. J Maternal Fetal Neonatal Med 32, 293-300.

Sinding M, Peters DA, Poulsen SS, Frøkjær JB, Christiansen OB, Petersen A, Uldbjerg N \& Sørensen A. (2018). Placental baseline conditions modulate the hyperoxic BOLD-MRI response. Placenta 61, 17-23.

Soothill PW, Nicolaides KH, Rodeck CH \& Campbell S. (1986). Effect of gestational age on fetal and intervillous blood gas and acid-base values in human pregnancy. Fetal Diagn Therapy 1, 168175 .

Soothill P, Nicolaides K \& Campbell S. (1987). Prenatal asphyxia, hyperlacticaemia, hypoglycaemia, and erythroblastosis in growth retarded fetuses. Br Med J (Clin Res Ed) 294, 1051-1053.

Sørensen A, Peters D, Fründ E, Lingman G, Christiansen O \& Uldbjerg N. (2013). Changes in human placental oxygenation during maternal hyperoxia estimated by blood oxygen leveldependent magnetic resonance imaging (BOLD MRI). Ultrasound Obstet Gynecol 42, 310 314.

Stacey T, Thompson JMD, Mitchell EA, Ekeroma AJ, Zuccollo JM \& McCowan LME. (2011). Association between maternal sleep practices and risk of late stillbirth: a case-control study. BMJ 342, 1350.

Stone_PR, Burgess W, Mclntyre J, Gunn AJ, Lear CA, Bennet L, Mitchell EA, Thompson JMD. (2017). J Physiol 595, 7441-7450. 
Sussman D, Saini BS, Schneiderman JE, Spitzer R, Seed M, Lye SJ \& Wells GD. (2019). Uterine artery and umbilical vein blood flow are unaffected by moderate habitual physical activity during pregnancy. Prenat Diagn 39, 976-985.

Talbert D \& Sebire N. (2004). The dynamic placenta: I. Hypothetical model of a placental mechanism matching local fetal blood flow to local intervillus oxygen delivery. Med Hypotheses 62, 511519.

Tamás P, Szilágyi A, Jeges S, Vizer M, Csermely T, Ifi Z, Bálint A \& Szabó I. (2007). Effects of maternal central hemodynamics on fetal heart rate patterns. Acta obstet gynecol Scand 86, 711-714.

Tchirikov M, Schröder H \& Hecher K. (2006). Ductus venosus shunting in the fetal venous circulation: regulatory mechanisms, diagnostic methods and medical importance. Ultrasound Obstet Gynecol 27, 452-461.

Thaler I, Manor D, Itskovitz J, Rottem S, Levit N, Timor-Tritsch I \& Brandes JM. (1990). Changes in uterine blood flow during human pregnancy. Am J Obstet Gynecol 162, 121-125.

Warland J \& Mitchell EA. (2014). A triple risk model for unexplained late stillbirth. BMC Pregnancy and Childbirth 14, 142.

Wojcieszek AM, Shepherd E, Middleton P, Gardener G, Ellwood DA, McClure EM, Gold KJ, Khong TY, Silver RM \& Erwich JJH. (2018). Interventions for investigating and identifying the causes of stillbirth. Cochrane Database of Systematic Reviews 4, CD012504.

Yadav BK, Neelavalli J, Krishnamurthy U, Szalai G, Shen Y, Nayak NR, Chaiworapongsa T, Hernandez-Andrade E, Than NG \& Haacke EM. (2016). A longitudinal study of placental perfusion using dynamic contrast enhanced magnetic resonance imaging in murine pregnancy. Placenta 43, 90-97.

You W, Andescavage N, Zun Z \& Limperopoulos C. (2017). Semi-automatic segmentation of the placenta into fetal and maternal compartments using intravoxel incoherent motion MRI. In Medical Imaging 2017: Biomedical Applications in Molecular, Structural, and Functional Imaging, pp. 1013726. International Society for Optics and Photonics.

Zun Z \& Limperopoulos C. (2018). Placental perfusion imaging using velocity- selective arterial spin labeling. Magn Reson Med 80, 1036-1047.

Translational perspective

Late stillbirth is independently associated with the maternal supine sleep position. Previous studies from our group had shown reductions in cardiac output and abdominal aortic blood flow when women assumed a supine position in late pregnancy. We had also shown that compared with being in state $2 \mathrm{~F}$ in the left lateral position, there was a $30 \%$ increased chance of the fetus being in $1 \mathrm{~F}$ and over a $60 \%$ reduction in $4 \mathrm{~F}$ during supine sleep. A switch to state $1 \mathrm{~F}$ or fetal quiescence when the mother was supine suggested the fetus was adopting a low oxygen-consuming state. In the current study, using novel MRI analytical technology, we sought to determine oxygen transfer across the placenta in healthy late gestation pregnancy, hypothesising that in the supine compared with the left lateral 
maternal position there would be a reduction in oxygen transfer to the fetus. The results confirmed a significant $23.7 \%$ reduction in total internal iliac arterial blood flow to the uterus in the supine position compared to left lateral and was associated with a significant reduction in an index we termed placental flux of $6.2 \%$ which described oxygen movement across the placenta to the fetus. In this study, the reductions in umbilical venous blood flow and fetal oxygen saturation in the supine position were not statistically significant. This study has shown that the maternal supine position in healthy late pregnancy does reduce oxygen transfer across the placenta and has provided a baseline for future studies assessing the impact of a physiological stressor such as maternal position on placental oxygenation. We speculate that vulnerable fetuses, such as those that are growth restricted and which may already be hypoxic, are unable to adapt to the stressor of maternal supine position change.

Author profile Journal of Physiology

\section{S Couper}

Finding passion for research so early on in one's career is a rare privilege that is not lost on me, nor is the endless support from my supervisors. As a medical student, this project has been pivotal in my limited career with further research and completing a PhD now high priorities. Perinatal health and women's health are areas of medicine that I hope to contribute to as a clinician and academic.

Through my exposure to, and experience of, research in these areas, I now see how important both are for any chance to change practice, and improve health outcomes.
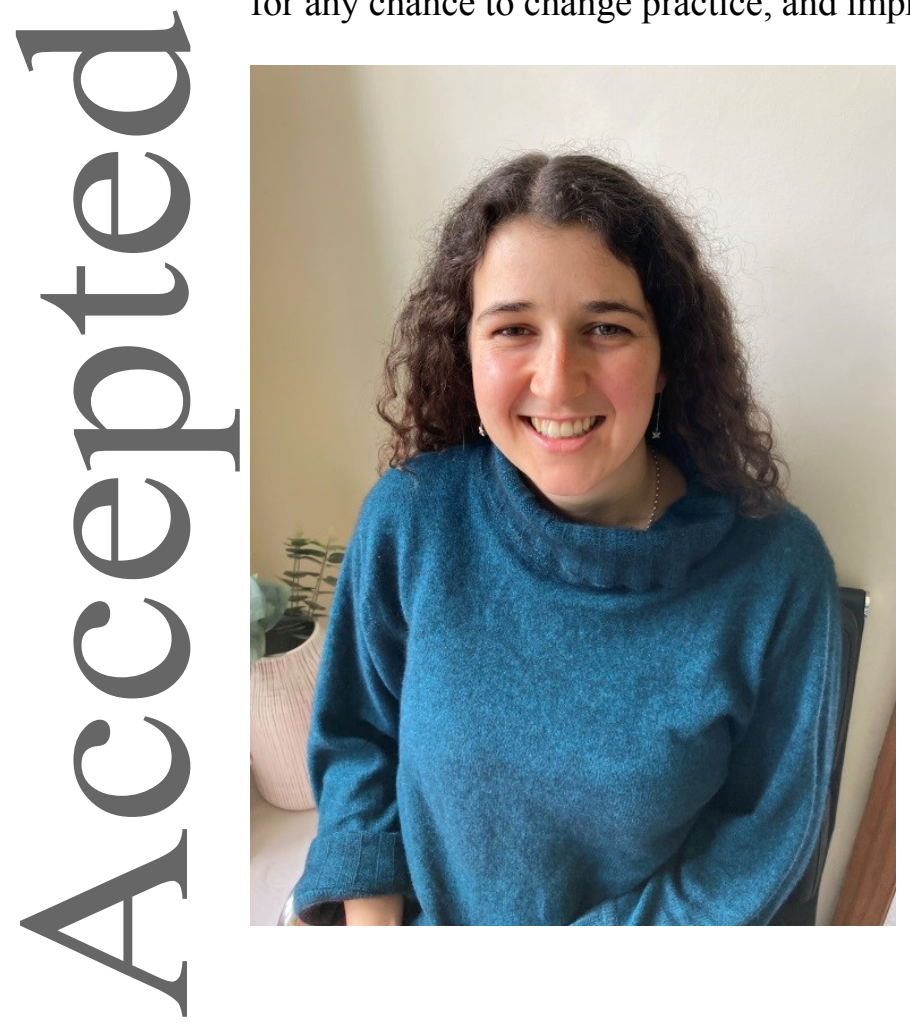